\title{
SCIENTIFIC EVALUATION OF SOME CONSOLIDATION MATERIALS OF EXCAVATED ARCHAEOLOGICAL POTTERY FROM THE REGION OF TEL PASTA AT SHARQIA IN THE EAST OF DELTA
}

\author{
Kamel, W. \\ Director of the follow-up for the restoration of Antiquities - Ministry of State for the Antiquities Affairs \\ e-mail:walid_elghareb@yahoo.com
}

Accepted 1/6/2012

\begin{abstract}
Many of the archaeological pottery objects excavated from the archaeological sites have suffered from different phenomena of deterioration. This kind of pottery needs a consolidation process for improving the physical and mechanical properties. Some archaeological pottery samples were obtained from the region of Tel pasta at Sharqia in the East of Delta, dating back to the Ptolemaic age. The pottery samples used in the study represent different models from the site for their use in Laboratory study. Scientific laboratory evaluation of some acrylic and silicon consolidation materials were done such as Monomer Poly Methyl Methacrylate, Paraloid B- 82, Ethyl Silicate Copolymer AS 21, a mixture of Ethyl Silicate Copolymer AS 21 and Paraloid B-82 and Tegovakon. Many experiments, tests and different examinations were done on The treated pottery samples such as determination of physical and mechanical properties, the examination of scanning electron microscope and thermal, light artificial ageing processes. Tests and experiments have all proved that one of two consolidants (First, a mixture of ethyl silicate copolymer AS21 and Paraloid B-82 at a rate of 1:1. Second, ethyl silicate copolymer AS21) must be used to consolidate archaeological pottery discovered from damp soil.
\end{abstract}

Keywords: Pottery, Poly Methyl Methacrylate, Paraloid B- 82, Examination, Consolidation

\section{Introduction}

Archaeological pottery has suffered from extreme impaired as a result to being buried in the soil for long periods up to thousands of years, which left behind many different phenomena of deterioration, the most dangerous of which is the poor physical structure [1], the pottery often needs a consolidation process that strengthens, links granules and improves the physical and mechanical properties of pottery objects by strengthening their internal structure using one of the various consolidation materials [2].The silicon materials are considered one of the best applied consolidants in the sphere of consolidating pottery, ceramics and glass objects particularly those excavated from damp soil [3]. The success of consolidants is based on the nature of objects, operating conditions and the nature of materials used in the consolidation. They bring their best results should they have a great ability to penetrate into the pores [4], with no occurrence of any future deterioration after treatment [5]. Also, they show protection of the object against the surrounding environmental factors [6], without relying on the trade 
name only [7]. But there must be knowledge of the properties of Consolidation material especially its chemistry, method of application and workability conditions [8], and they

\section{Materials and methods of study}

\section{1. study materials}

Some of the pottery samples were selected from the fragments excavated from the Tel Pasta archaeological site, apart from preparing many manufactured pottery samples to apply to the nature of the tests used as shown in fig. (1). Some consolidation processes were experimented on the samples by using the following consolidants: * Paraloid B-82 (Monomer Poly Methyl Methacrylate) must be experimentally tested before being applied [9] to select the best and they must be characterized by stability and no change [10].

dissolved in toluene at a concentration of $5 \%$, *Ethyl Silicate Copolymer AS 21 in its solution nature, *Mixture of Ethyl Silicate Copolymer AS 21 and Paraloid B- 82 at a rate of $1: 1$ and $*$ Tegovakon in its solution nature. These materials were applied according to what is reported previously by many researchers [11] [12] [13] [14] [15].

Figure (1) pottery samples used in experiments and laboratory tests.

\subsection{Method of consolidation}

Pottery

samples

were

consolidated through immersion method according to what is reported by both Sutherland, (1999) [16] and Dowman, (1970) [17]. The treated samples were tested, examined and being compared to the untreated samples by performing the following tests: $\underline{\mathbf{A}}$ - Determination of physical and mechanical properties according to
ASTM [18]. $\underline{\mathbf{B}}$ - Examination of pottery samples by scanning electron microscope. Artificial ageing test (Thermal - light by U.V- salt weathering) in accordance with Madkour, (2004) [19], and Kamel (2007) [20] were done and the samples were re-evaluated by scanning electron microscope.

\subsection{Results}

\subsection{Determination of physical and mechanical properties of treated samples}

3.1.1. Determination of the Degree of Water Absorption.

The results of the determination of water absorption of the treated samples being compared to the untreated one show that a mixture of Ethyl Silicate Copolymer AS 21 and Paraloid B-82 achieved the best results, recording 5.26
$\%$, followed by Ethyl Silicate Copolymer AS $217.88 \%$, and Paraloid B-82 $10.53 \%$, then Tegovakon which recorded a water absorption degree $13.84 \%$, after that, monomer poly methyl Methacrylate $15.25 \%$, and finally the untreated pottery 
sample recording a degree of water absorption $23.66 \%$, as shown in fig. (2). A mixture of Ethyl Silicate Copolymer AS 21 and Paraloid B-82 recorded a percentage of reducing a water absorption degree estimated at $77.76 \%$, and The percentage of reducing the degree of

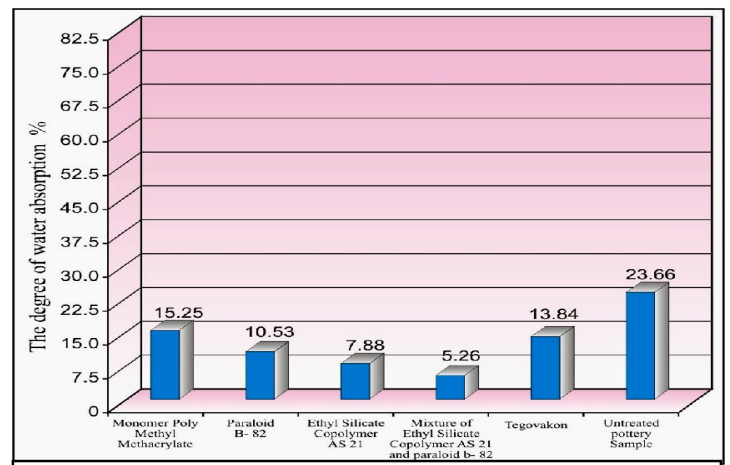

Figure (2) degree of water absorption of the pottery samples treated with selected consolidation materials. water absorption for Ethyl Silicate Copolymer AS 21 was $66.69 \%$, but Paraloid B-82 recorded a percentage of reducing the water absorption degree $55.49 \%$, for Tegovakon recorded 41.50 $\%$., and for monomer poly methyl Methacrylate recording $35.54 \%$, fig. (3).

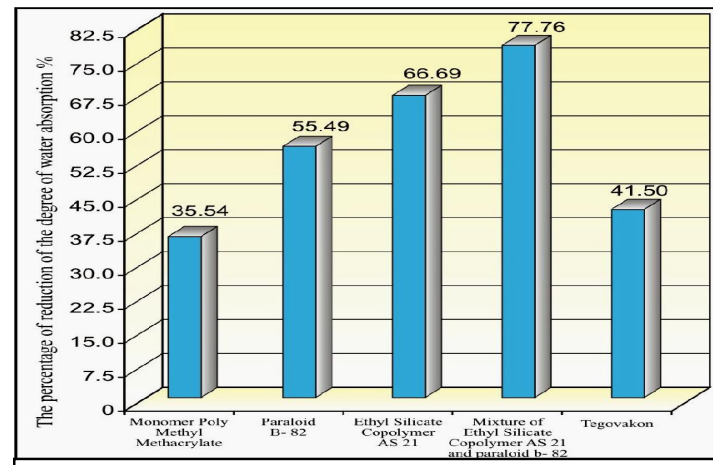

Figure (3) percentage of the reduction of the degree of water absorption of the pottery samples treated with selected consolidation materials.

\subsubsection{Determination of the Degree of Apparent porosity}

It is obvious from the results of determination of the degree of apparent porosity of the treated samples being compared to the untreated samples that a mixture of Ethyl Silicate copolymer AS 21 and Paraloid B-82 has achieved the best results, recording a degree of Apparent porosity $11.11 \%$, followed by Ethyl Silicate copolymer AS 21 recording $14.34 \%$, then Paraloid B-82 recording $18.39 \%$, followed by Tegovakon recording $20.54 \%$, after that monomer poly methyl

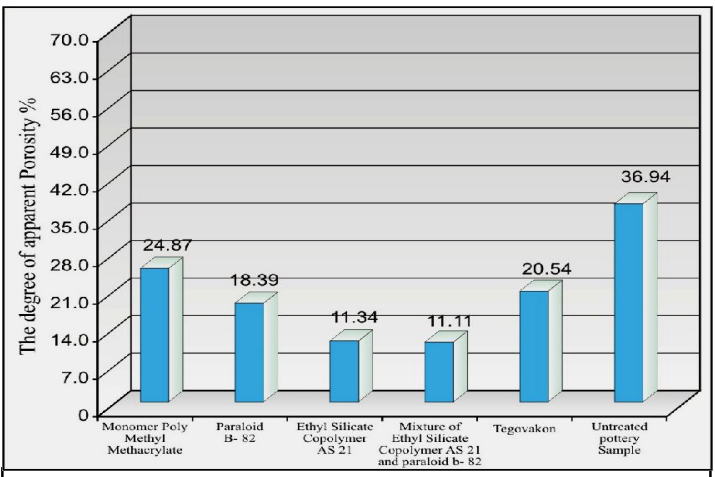

Figure (4) degree of apparent porosity of the pottery samples treated with selected consolidation materials.
Methacrylate $24.87 \%$, and finally the untreated pottery sample recording $36.94 \%$, fig. (4). A mixture of Ethyl Silicate Copolymer AS 21 and Paraloid B-82 recorded a percentage of reducing the degree of apparent porosity 69.92 $\%$, and for Ethyl Silicate Copolymer AS 21 recording $61.18 \%$, and concerning Paraloid B-82 recorded $50.21 \%$, but Tegovakon recorded 44.39 $\%$, while monomer poly methyl Methacrylate recorded $32.67 \%$, fig. (5)

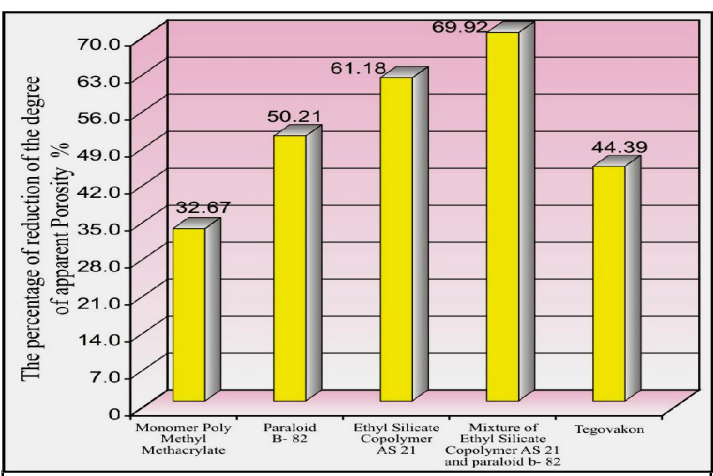

Figure (5) percentage of the reduction of the degree of apparent porosity of the pottery samples treated with selected consolidation materials 
3.1.3. Degree of compressive strength of the treated pottery samples.

The results of the determination of recording $84.73 \mathrm{~kg} / \mathrm{cm}^{2}$, after that resistance to pressure for samples treated with selected consolidants being compared to the untreated samples proved that the selected consolidants improved the mechanical properties of the samples. This result represents the average numbers of the results for the three samples for each treatment, Paraloid B-82 recorded a compressive strength degree $181.50 \mathrm{~kg} / \mathrm{cm}^{2}$, followed by a mixture of Ethyl Silicate copolymer AS 21 and Paraloid B-82 recording $151.60 \mathrm{~kg} / \mathrm{cm}^{2}$, then Ethyl Silicate copolymer AS 21 recording 115.11 $\mathrm{kg} / \mathrm{cm}^{2}$, followed by Tegovakon

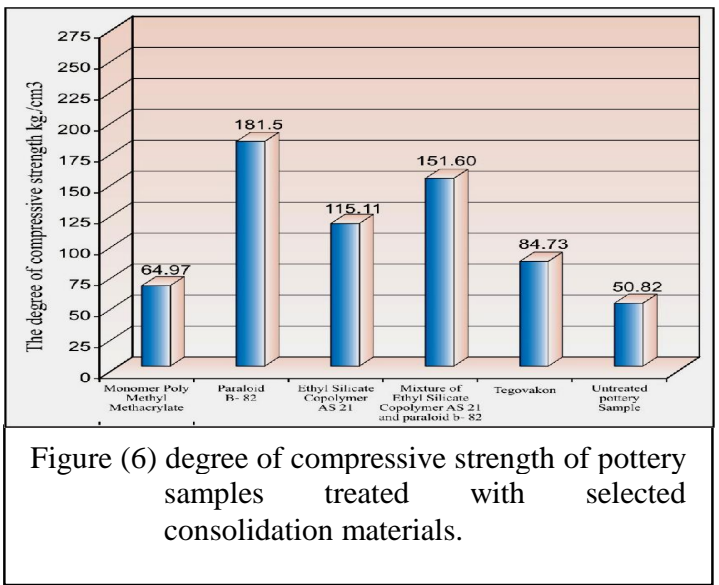

\subsubsection{Examination by SEM}

Obviously, through the results of examination by scanning electron microscope, Paraloid B-82 had spread properly and penetrated into the pores, and it linked the particles with each other, depositing densely between the pores, fig. (8). It was as well noted that it achieved full homogeneity and it spread throughout the sample. Hence, it achieved an equally strong cohesion of the grains. Thus, making the sample well resistant to different factors of deterioration. Spreading, the linking of granules, packaging, and homogeneity are some of the most important features of selected consolidation materials. As

monomer Poly Methyl Methacrylate recording $64.97 \mathrm{~kg} / \mathrm{cm}^{2}$, and finally the untreated sample recorded $50.82 \mathrm{~kg} / \mathrm{cm}^{2}$, fig. (6). The percentage of the compressive strength of the treated samples being compared to the untreated samples have ranged from $19.97 \%$ as in the case of the treated sample with monomer poly methyl Methacrylate to $257.14 \%$, as in the case of the treated sample with Paraloid B-82, and these two values have got between them the percentages for the rest of the treated samples, fig. (7).

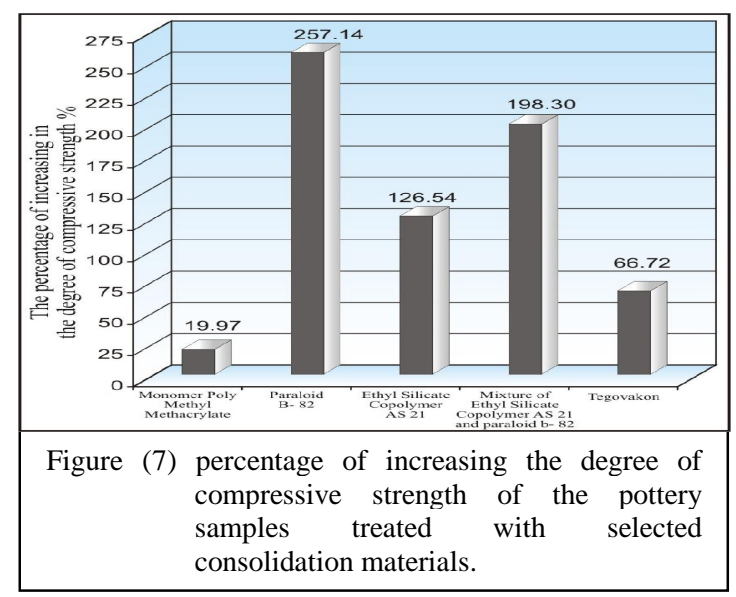

shown through the examination by scanning electron microscope of the sample treated with monomer poly methyl Methacrylate (PMMA) that it spread and penetrated partially within the pores and gaps of the sample, without the grains being fully packaged, which made its consolidation impaired, fig. (9). A mixture of Ethyl Silicate Copolymer AS 21 and Paraloid B- 82 at a rate of 1: 1 and Ethyl Silicate Copolymer AS 21 spread inside the pores, linking and packaging the grains, as well as forming cross-links in the form of a network structure, fig. (10). This gave a strong coherence and cohesion of the grains. Yet, consolidation 
material formed a thick film covering the surface, but unfortunately, this film was cracked, as mentioned (Brus and Kotlik) (21) owing to the presence of some

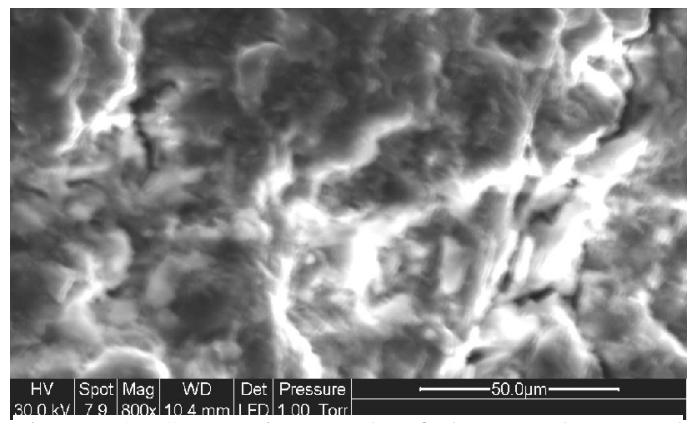

Figure (8) SEM micrograph of the sample treated with Paraloid B-82 shows that it spread and penetrated into the pores well, and linked the particles with one another, depositing densely between the pores. unstable catalysts, fig. (11). Tegovakon spread inside the pores and gaps imperfectly, because it did not fill all the pores and gaps of the sample, fig. (12).

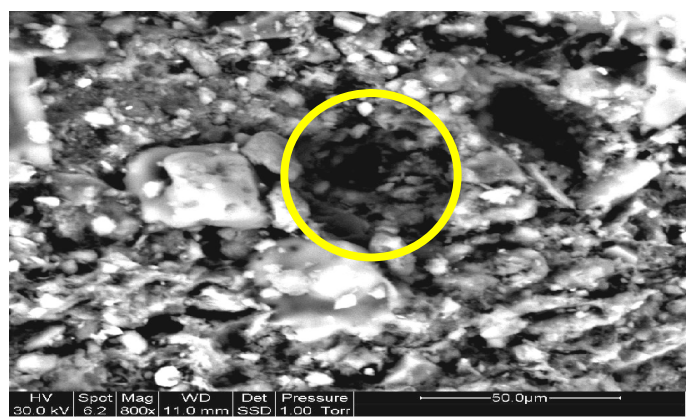

Figure (9) SEM micrograph of the sample treated with poly methyl Methacrylate shows that it spread partially and penetrated within the pores and gaps of the sample.

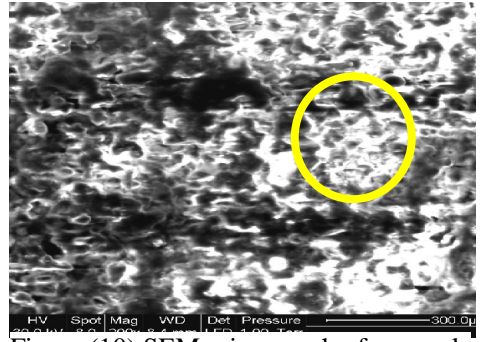

Figure (10) SEM micrograph of a sample treated with a mixture of Ethyl Silicate copolymer AS 21 and Paraloid B-82 shows its spreading inside the pores, linking and packaging the grains, and forming cross-links in the form of a network structure.

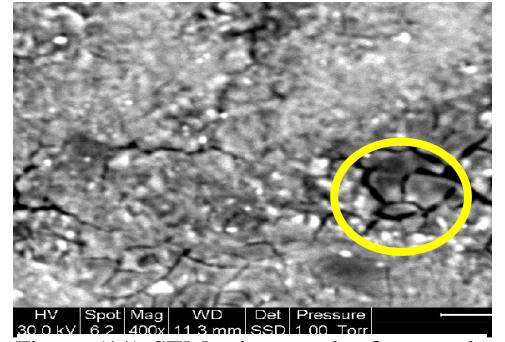

Figure (11) SEM micrograph of a sample treated with Ethyl Silicate Copolymer AS 21 shows that it spread and penetrated within the pores and gaps of the sample, but this consolidation materia formed a thick film covering

the surface that was cracked.

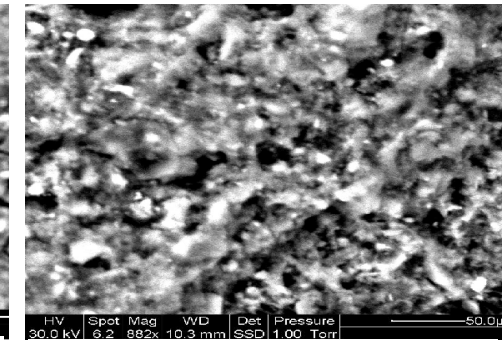

Figure (12) SEM micrograph of a sample treated with Tegovakon shows that it spread inside the pores and gaps imperfectly.

\subsubsection{Accelerated artificial ageing affecting pottery samples after treatment}

\subsubsection{Thermal artificial ageing}

Thermal artificial ageing test was done according to Madkour (2004) and Kamel (2007), it showed that Paraloid B82 recorded the highest degree of resistance to thermal artificial ageing, but it did show a loss in weight by $0.75 \%$ while the percentage of loss in weight rose to $2.85 \%$ as in the case of the samples treated With Tegovakon being compared to the untreated sample recording a loss in weight by $25.87 \%$, fig. (13).

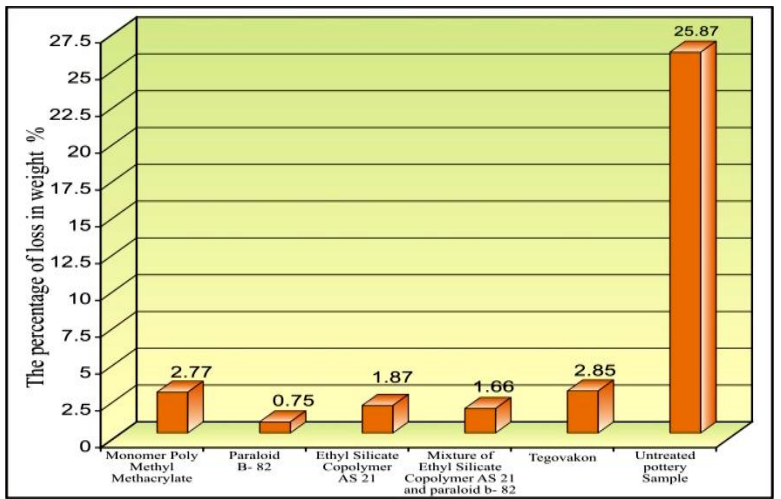

Figure (13) the percentage of weight loss in treated pottery samples with by thermal artificial ageing. 


\subsubsection{Light artificial ageing by ultraviolet radiations (U.V).}

It is evident from the results of exposure to ultraviolet radiations that the treated samples did not undergo any change in the color and appearance of the surface, but they experienced a loss in the weight. The percentage of loss in weight of the mixture of Ethyl Silicate
AS21 and Paraloid B-82 was $0.24 \%$ and the percentage of loss in weight went up to $2.50 \%$ as in the case of the samples treated with Tegovakon, being compared to the untreated sample recording a loss in weight $4.08 \%$, fig. (14).

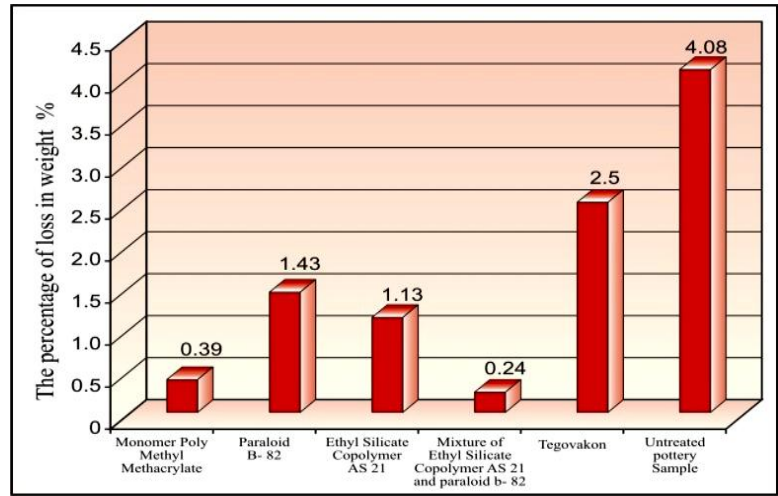

Figure (14) the percentage of weight loss in treated pottery samples by light artificial ageing by U.V

\subsubsection{Artificial ageing by salt weathering}

The results of salt weathering showed that all the samples were impacted on by salt weathering with sodium chloride at a concentration of $10 \%$, it was also observed that some samples have experienced a very slight change ( semi-darkness) such as the samples treated with Paraloid B-82, while the samples treated with monomer Poly Methyl Methacrylate, a mixture of ethyl silicate copolymer AS21 and Paraloid B-82 and ethyl silicate copolymer AS21 have remained Without any change in the color and appearance of the surface. But most of the samples have suffered from a loss in weight at different rates. The mixture of Ethyl Silicate copolymer AS21 and Paraloid B-82 has achieved the best results recording a percentage of loss estimated at $0.27 \%$, and ethyl silicate copolymer AS21 recording a percentage of loss by $0.30 \%$, while the percentage of loss in weight has gone up to $12.29 \%$ as in the case of samples treated with monomer Poly Methyl Methacrylate being compared to the untreated sample that has experienced weakness and separation of the grains, therefore it lost about $36.92 \%$, fig. (15).

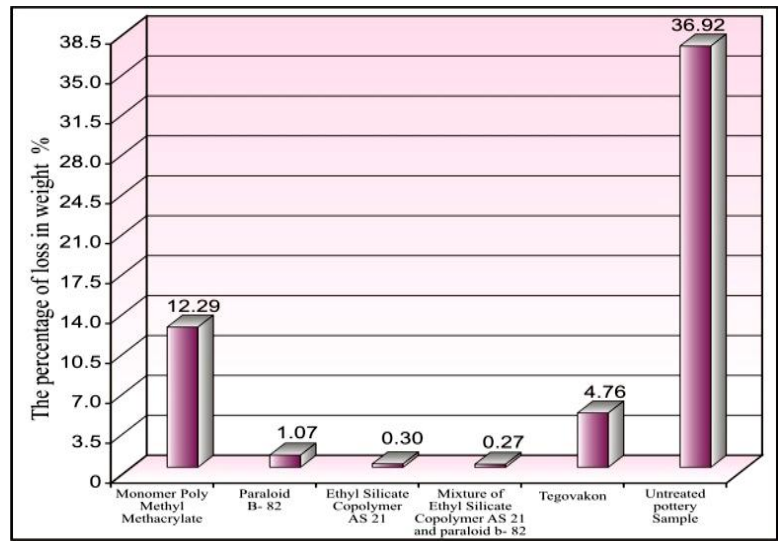

Figure (15) the percentage of weight loss treated pottery samples by artificial ageing of salt weathering. 


\subsubsection{Examination the treated samples after artificial ageing by SEM}

Through the examination by scanning electron microscope It could be observed that the sample treated with Paraloid B-82 that, despite being exposed to the factors of artificial ageing, Paraloid B-82 is still spreading inside the pores, linking the grains altogether, and packaging them in a part of the sample. But it failed to package or link the grains in another part of the sample, so, there appeared large grains uncorrelated and non-coherent together, fig. (16). The examination by scanning electron microscope of the sample treated with PMMA shows that it is impacted by factors of artificial ageing. That is why it had increased gaps and a reduced amount or a percentage of the consolidation

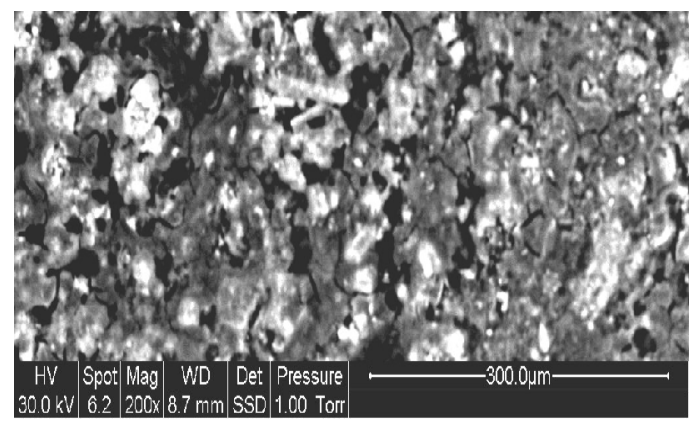

Figure (16) SEM photomicrograph of sample treated with Paraloid B-82 shows that it is still spreading inside the pores, linking the grains with each other, and packaging them in one part of the sample. material inside the pores fig. (17). And it became clear through the examination by scanning electron microscope of the samples treated with Ethyl Silicate Copolymer AS 21 and a mixture of Ethyl Silicate Copolymer AS 21 and Paraloid B-82 that the treated samples still had their strength and cohesion of the particles, in spite of the cracking film of consolidation materials, fig. (18-19). It was shown through the examination by scanning electron microscope of the sample treated with Tegovakon that the sample had been impacted by factors of artificial ageing. Thence the particles were separated from one another and the sample had more gaps, fig. (20).

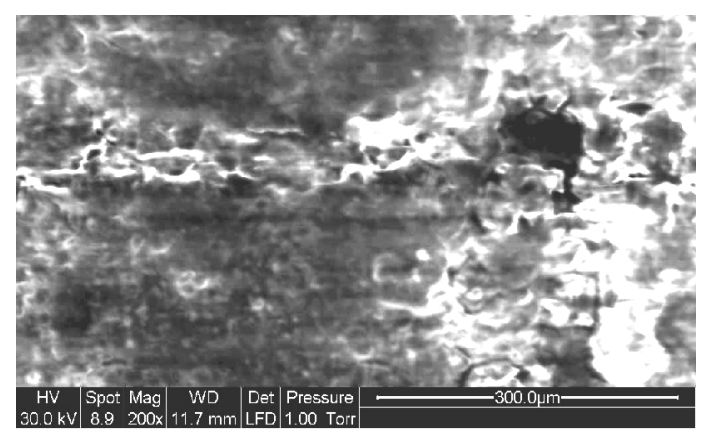

Figure (17) SEM photomicrograph of sample treated with Monomer Poly Methyl Methacrylate shows increased gaps and a reduced amount of the consolidation material inside the pores.

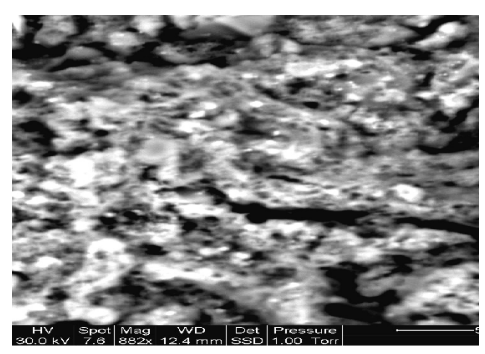

Figure (18) SEM photomicrograph of a sample treated with Ethyl Silicate Copolymer AS 21 shows that the treated sample retained its strength and cohesion of the particles

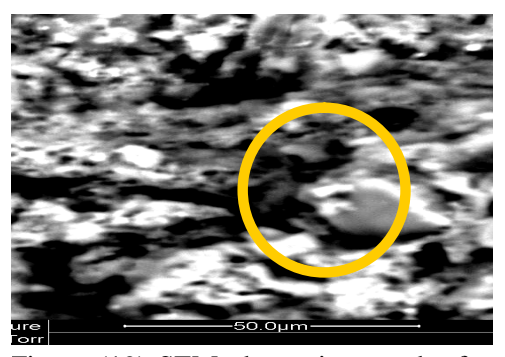

Figure (19) SEM photomicrograph of a sample treated with Ethyl Silicate Copolymer AS 21And Paraloid B - 82 shows that the treated sample retained its strength and cohesion of the particles as a network structure.

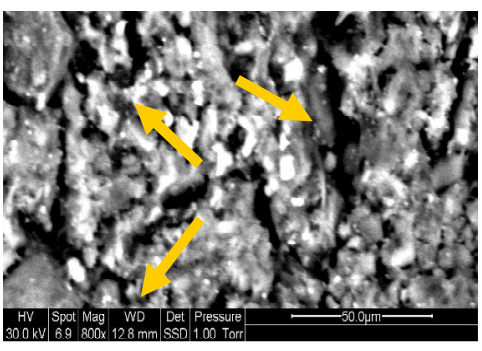

Figure (20) SEM photomicrograph of a sample treated with Tegovakon shows artificial ageing affecting, as a particles separation and increasing its gaps

\section{Discussion}

The results of experiments of the physical properties of pottery samples treated with some selected consolidants showed that most of the consolidation materials did not affect the general appearance of the treated pottery samples having been compared with the untreated samples except for ethyl silicate 
copolymer AS21 and a mixture of ethyl silicate copolymer AS21 and Paraloid B82 that experienced a slight change in color (darkness). It experimentally clear that all selected consolidants had improved physical properties of the treated pottery samples, but in different degrees. The results of the determination of water absorption and porosity of the treated samples proved that the selected consolidants had improved physical properties as mentioned above. A mixture of ethyl silicate copolymer AS 21 and Paraloid B-82, then ethyl silicate copolymer AS21, after that Paraloid B82, then Tegovakon and finally monomer PMMA have successively achieved the best results. As the mechanical properties, the experiments and laboratory tests have proved that the selected consolidants have also improved the mechanical properties of the treated samples compared with the untreated samples, for this reason, the consolidants have linked and strengthened the grains (the internal structure) and the selected consolidants give the treated samples more resistant to compression strength. Paraloid B-82 has shown the best results of resistance to compressive stress, followed by a mixture of ethyl silicate copolymer AS21 and Paraloid B-82, later, ethyl silicate copolymer AS21, then, Tegovakon and finally, poly methyl Methacrylate have successively achieved the best results. The examination by scanning electron microscope (SEM) of the samples treated with the selected consolidants proved that Paraloid B-82, followed by a mixture of ethyl silicate copolymer AS21 and Paraloid B-82 had given excellent results ,then ethyl silicate copolymer AS21 had given good results, but Tegovakon and poly methyl Methacrylate (PMMA) gave no satisfactory results. It is scientifically known that the stability of the samples treated with these consolidants against the factors of accelerated artificial ageing is sufficient evidence of its success in the process of treatment and conservation. The results of experiments of accelerated thermal artificial ageing have shown that the samples treated with selected consolidants have indicated stability and resistance to thermal artificial ageing after being compared with the untreated samples. To begin with, Paraloid B-82, then a mixture of ethyl silicate copolymer AS21 and Paraloid B-82, later, ethyl silicate copolymer AS21, then monomer Poly Methyl Methacrylate, and finally, Tegovakon have all successively shown the best results. While the results of experiences and tests of accelerated artificial ageing by U.V proved that the samples treated with the selected consolidation materials have shown stability against the artificial ageing by ultraviolet radiations (U.V), but in different degrees. A mixture of Ethyl Silicate Copolymer AS21 and Paraloid B82. Then Ethyl Silicate Copolymer AS21, later, monomer Poly Methyl Methacrylate, and finally Tegovakon have all successively shown the best results of the resistance to accelerated artificial ageing by U.V. The results of experiments and tests of accelerated artificial ageing by salt weathering have shown that the samples treated with a mixture of Ethyl Silicate Copolymer AS21 and Paraloid B-82, then ethyl silicate copolymer AS21, after that, Paraloid B-82, later, Tegovakon, and finally, monomer Poly Methyl Methacrylate experienced no change in the color or appearance of the surface of the samples. A mixture of Ethyl Silicate Copolymer AS21 and Paraloid B-82, then Ethyl Silicate Copolymer AS21 have both shown the best results of resistance to salt weathering accelerated artificial ageing, and the examination by scanning electron microscope (SEM) has also confirmed the same results.

\section{Conclusion}

Through the discussion of the abstracted results of the research, it could be recommend using one of the following two consolidants: First, a mixture of ethyl silicate copolymer AS21 and Paraloid B-82 at a rate of 1:1. Second, ethyl silicate copolymer AS21, one of them must 
be used to consolidate archaeological pottery discovered from the excavations, as it was shown by the experimental study on the excavated pottery fragments from the region of antiquities of $\mathrm{Tel}$ pasta at Sharqia in the east of delta. The treatment has improved the physical and mechanical properties of the treated samples and it has made them highly more resistant to accelerated artificial ageing. And it has done a high degree of penetration into the pores of the sample. This applies to what the authorities and scientific organizations approved of. This trend needs more scientific studies and researches on different pottery samples from several archaeological sites using other consolidants for a continued development.

\section{References}

[1] Jonathan, A. (1987). Adhesive and coatings in Science for conservators, Vol. 3 Museums \& Galleries Commission, London.

[2] Moncrieff, A., (1976). The treatment of deteriorating stone with silicone resins, Studies in Conservation, Vol. 21 (4), pp: 179191.

[3] Newton, R. \& Sedden, A., (1999). Organic coating for medieval glass: in Tennent, N. (Ed.), the conservation of glass and ceramics, James \& James, London

[4] Torraca, G., (1982). Porous building materials, ICCROM, Rome

[5] Larsen, K., \& Marstein, N., (2000). Conservation of historic timber structure, Butterworth Heinemann, Oxford

[6] Pascua,N. G., Derojasm, I. \& Faris, M., (1995). Study of porosity and physical properties as method to establish the effectiveness of treatment, in: Methods of evaluating products for the conservation of porous building materials in monument, ICCROM, Rome, pp: 147- 162

[7] King, E., (1989). The use of resins, in: (Eds.) Ashurst, J, and Ashurst, N. Practical building conservation, Vol. 5, London, pp: 71- 79

[8] Dewhite, E., (1982). Resins in conservation, in: Tate, J. Tennent, N. \& Townsend J. (Ed.) The Proceeding of the symposium resins in conservation, Scottish society for conservation and restoration, Edinburgh, pp: 1 - 5
[9] Carbonara, G., (1996). The integration of the image problems in the restoration of monument, in: (Eds.) Price, N., \& Taller, M. Historical and philosophical issues in the conservation of cultural heritage, USA, pp: 236-243.

[10] McNeill, I., (1992). Fundamental aspects of polymer degradation, in: (Eds.) Allen, N., Edge, M., \& Horie, C., Polymers in conservation, London, pp: 14- 31

[11] Horie, C., (1987). Materials for conservation-adhesives, consolidants and lacquers, Butterworths, London

[12] Koop, S., (1986). The use of Paraloid B-72 as an adhesive: its application for archaeological ceramics and other materials, Studies in Conservation, Vol. 31 (1), pp: 7-14.

[13] Kotlik, P., Ignas, P., \& Zelinger, J., (1980). Some ways of polymerization of Methyl Methacrylate, Studies in Conservation, Vol. 25 (1), pp: 1-13.

[14] Nishiura, T., (1995). Experimental evaluation of stone consolidation used in Japan, in: Method of evaluating products for the conservation of porous building material in monuments, ICCROM, Rome, pp: 189-202.

[15] Brus, J., \& Kotlik, P., (1996). Consolidation of stone by mixture of Alkoxy Silane and Acrylic polymers, Studies in Conservation, Vol.41 (2), pp: 109-119.

[16] Sutherland, A., (1998). Lecture on field conservation techniques at 
Kafer Hassan Dawood, Excavation Season.

[17] Dowman, E., (1970). Conservation in field archaeology, Methuen young books, London.

[18] Annual Book of ASTM Standards (2001). Section 15, part 15-02: Glass, ceramics and white wares, USA

[19] Madkour, F., (2004). Study materials and modern methods used in the restoration and maintenance of the monuments of Islamic ceramic with practical application to some selected models, Ph.D. Thesis, Conservation dept., Faculty of Archeology, Cairo University

[20] Kamel, W., (2007). The scientific evaluation of effect of techniques of manufacture of pottery objects on rates of their deterioration in some different archaeological sites Ph.D. Thesis, Conservation dept., Faculty of Archeology, Cairo University

[21] Brus, J., \& Kotlik, P., (1996). Cracking of organo silicone stone consolidants in gel form, Studies in Conservation, Vol.41 (1), pp: 55-59. 